\title{
Effects of Social and Outcome Expectancies on Hazardous Drinking among Chinese University Students: The Mediating Role of Drinking Motivations
}

\author{
Meng Xuan ZHANG ${ }^{\mathrm{a}}$
}

Lisbeth $\mathrm{KU}^{\mathrm{b}}$

Anise M.S. WU

Shu M. YU

Ivan Jacob Agaloos PESIGAN ${ }^{\mathrm{a}}$

a Department of Psychology, Faculty of Social Sciences (FSS), University of Macau, Avenida da Universidade, Taipa, Macau, China.

${ }^{\mathrm{b}}$ School of Applied Social Sciences, Faculty of Health and Life Sciences, De Montfort University, The Gateway, Leicester, LE1 9BH, United Kingdom.

\section{Corresponding author:}

Dr. Anise M. S. Wu, Professor, Department of Psychology, Faculty of Social Sciences, University of Macau, Avenida da Universidade, Taipa, Macau, China.

E-mail: anisewu@um.edu.mo

Phone: +(853) 88228377

Fax: $+\mathbf{8 5 3 - 8 8 2 2 - 2 3 3 7}$ 
Effects of Social and Outcome Expectancies on Hazardous Drinking among Chinese University Students: The Mediating Role of Drinking Motivations 


\begin{abstract}
Background and Objectives: Based on the theory of reasoned action, the present study investigated the relative effects of drinking outcome expectancies and parental norms, as well as the mediating effect of drinking motivations, on hazardous drinking in Chinese university students.
\end{abstract}

Method: A sample of Chinese university students in Hong Kong and Macao ( $N=973$, $\mathrm{M}=19.82, \mathrm{SD}=1.57,48.9 \%$ males), who reported drinking in the past 3 months, voluntarily completed an anonymous questionnaire. Path analysis was used to test the effects of the variables on hazardous drinking.

Results: All the psychosocial variables showed positive correlations with hazardous drinking. In the path model, controlling for sex, parental norms had both direct and indirect effects on hazardous drinking through social and enhancement motivations. Courage had the strongest indirect effect on drinking behavior through social, enhancement, and coping motivations, whereas the relationship between tension reduction and hazardous drinking was mediated by enhancement and coping motivations. Sociality and sexuality only had indirect effect through social and coping motivations respectively. Negative outcome expectancies had no direct nor indirect effects on hazardous drinking.

Conclusions: Perceived approval from parents and positive alcohol outcome expectancies may enhance individuals' tendency to engage in hazardous drinking by increasing their motivation to drink to be social, for enjoyment, and to cope with problems. Parents should explicitly show their disapproval of their children's drinking, and education efforts should focus on decreasing positive outcome expectancies and associated motivations for drinking among Chinese university students.

Keywords: Hazardous alcohol use; Parental norms; Outcome expectancies; Drinking motivations; University students; Chinese 


\section{Introduction}

Hazardous drinking is commonly referred to in terms of quantity and frequency of alcohol consumption that increase risks for both short-term and long-term adverse health consequences (Ji, Hu, \& Song, 2012; Mallett et al., 2013; Reid, Fiellin, \& O'Connor, 1999; White \& Hingson, 2013; World Health Organization [WHO], 2014). Examples include heavy episodic drinking (i.e., over 60 grams [six drinks] on a single occasion within a short period of time, commonly one month; WHO, 2014) and binge drinking (i.e., $\geq 5$ drinks for male and $\geq 4$ drinks for female on one occasion; (Olthuis, Zamboanga, Ham, \& Van Tyne, 2011). Studies commonly assess hazardous drinking by validated measures such as the Alcohol Use Disorder Identification Test (AUDIT; Babor, Higgins-Biddle, Saunders, \& Monteiro, 2001). Hazardous drinking among university students has been an increasing public health concern because of its high prevalence and associated negative consequences. For example, nearly $50 \%$ of university students in the US reported engaging in heavy episodic drinking in the past 2 weeks (Montauti \& Bulmer, 2014), whereas in England, 40\% of university students were classified as hazardous drinkers (by AUDIT; Heather et al., 2011). Hazardous drinking not only impairs attention and memory, but it is also related to a wide range of severe physiological, social, and economic problems in university students (Howland et al., 2010; Leavens, Leffingwell, Miller, Brett, \& Lombardi, 2017). For instance, students who engaged in hazardous drinking were found to report more injuries and aggressive behaviors than students who did not engage in such drinking (Dunne \& Katz, 2015; Giancola, 2002).

Empirical research on university students' alcohol use in China is relatively scarce. One study reported that $11.2 \%$ of Chinese university students were hazardous drinkers (by AUDIT), and their physical and mental health being was adversely affected (Xu \& Deng, 2016). Another two surveys showed that $23.5 \%$ and $13.8 \%$ of the university students engaged in binge drinking ( $\geq 5$ drinks on a single occasion in the past year) in mainland China and 
Hong Kong respectively (Ji et al., 2012; Kim et al., 2009). Given the increasing trend of alcohol consumption in Chinese populations (Tang et al., 2013), the prevalence of, and associated problems with, hazardous drinking is expected to worsen in coming years. There is, however, a lack of knowledge regarding psychological risk and protective factors regarding hazardous drinking among Chinese university students. In the framework of the theory of reasoned action (TRA), this study aimed to identify cognitive factors associated with hazardous drinking among Chinese university students that may be useful in designing effective intervention.

\section{Theory of Reasoned Action (TRA)}

The reasoned action approach is a well-known theoretical framework for explaining and predicting health risk behaviors, including smoking, binge drinking, and illicit drug use (Conner, McEachan, Lawton, \& Gardner, 2017; Fishbein \& Ajzen, 2011; McEachan et al., 2016). According to this approach, personal beliefs motivate humans to engage in a behavior (Fishbein \& Ajzen, 2011). One of the major theories derived from this approach is TRA, which proposes two cognitive determinants of a volitional behavior: attitudes towards and subjective norms for that behavior (Fishbein \& Ajzen, 2011). Attitudes emerge from an evaluation of the expected positive and negative outcomes (i.e., outcome expectancies) of performing the behavior, while subjective norms are formed by pressure stemming from the beliefs one holds regarding significant others' (e.g., parents, partners, and peers) expectations regarding one's behavior. Favorable outcome and social expectancies are expected to increase one's motivation or intention to engage in a behavior and thus increase the likelihood of him/ her engaging in that behavior.

TRA has been satisfactorily applied to university drinking in Western samples, such as Spanish and American students, and both attitudes and subjective norms have been shown to be significant factors of both alcohol use and its problematic use (Espada, Griffin, Gonzalvez, 
\& Orgiles, 2015; Fostera, Dukes, \& Sartor, 2016). However, previous studies that have applied TRA to university drinking assessed only a general attitude toward drinking, rather than making a comprehensive examination of its antecedent outcome expectancy beliefs. In order to gain information to design more effective intervention, we compared the effects of various outcome expectancies of drinking (i.e., sociability, tension reduction, liquid courage, sexuality, cognitive and behavioural impairment, risk and aggression, self-perception; Anthenien, Lembo, \& Neighbors, 2017) and subjective (parental) norms toward drinking behaviors on drinking motivations and hazardous drinking among Chinese university students.

\section{Alcohol Outcome Expectancies}

Outcome expectancies regarding alcohol use refer to individuals' beliefs about what they will experience after they consume alcohol. These expectancies are divided two categories: positive and negative alcohol expectancies. Examples of positive alcohol expectancies include feeling more sexually appealing, reducing tension, and feeling more confident, whereas negative alcohol expectancies include a tendency to engage in aggressive acts, feel sick, and have slower physical reactions (Anthenien et al., 2017). Compared to older, nonstudent participants, university students tend to possess more expectancies regarding particular positive alcohol outcomes (i.e., social improvement and tension reduction; Monk \& Heim, 2016).

Consistent with TRA, alcohol outcome expectancies have been found to be significantly associated with alcohol use and its negative consequences among youth (Fishbein \& Ajzen, 2011; Ham, Stewart, Norton, \& Hope, 2005). Positive correlations between positive alcohol outcome expectancies and alcohol use have been also observed among Chinese adolescents and Asian American university students (Chen et al., 2011; Han \& Short, 2009; Ting, Chen, Liu, Lin, \& Chen, 2015). Problematic drinkers tend to have positive outcome expectancies 
regarding immediate effects of hazardous drinking (e.g., emotional arousal and relaxation) and tend to ignore the long-term negative consequences (e.g., impairment of social function; Lewis \& O'Neill, 2000). However, findings regarding negative outcome expectancies and hazardous drinking were less conclusive. A systematic review found that people with more negative outcome expectancies were less likely to consume alcohol (Jones, Corbin, \& Fromme, 2001), whereas a study among college students found a positive correlation between negative outcome expectancies and hazardous alcohol use (Zamboanga, Schwartz, Ham, Borsari, \& Van Tyne, 2010). In the existing literature, alcohol outcome expectancies and its association with hazardous drinking has not been empirically examined among Chinese university students.

\section{Perceived Parental Norms}

Perceived parental norms is a major type of subjective norm and specifically refers to the social expectations of one's parents toward one's behavior (e.g., approval or disapproval of one's drinking; Neighbors et al., 2008). In existing literature, university drinking is most often positively associated with favorable perceived peer norms (LaBrie, Lac, Kenney, \& Mirza, 2011; Phua, 2011; Zehe, Colder, Read, Wieczorek, \& Lengua, 2013). Very few studies have investigated the association between perceived parental norms and university students' drinking (Lac \& Donaldson, 2018; Perkins, 2002).

Parents are one of the most important reference groups for students during the transition from the high school to college; students begin to take on the adult roles, and parental norms may be influential in both direct (i.e., communicating their expectations) and indirect (i.e., student observes parents' behaviors) ways on their behaviors (Perkins, 2002). Asian Americans students were found to be less likely than their Caucasian counterparts to perceive their important others (e.g., parents) as approving of their drinking (Nguyen \& Neighbors, 2013), which suggests potential cultural differences. Given emphasis on familism by the 
culture, it is likely that Chinese students' health behaviors would be influenced by their parental norms (e.g., physical activity; Wu \& Jwo, 2005). In keeping with the tenets of TRA, we hypothesized that perceived parental approval regarding drinking would be linked to hazardous drinking among university students.

\section{Drinking Motivations}

According to TRA, both beliefs regarding behavioral outcomes and significant others' approval of a specific behavior would motivate an individual to perform that behaviors (Fishbein \& Ajzen, 2011). Drinking motivations are the basic drives underlying the decision to drink and subsequent drinking behaviors (Bruce, Curren, \& Williams, 2012). Based on Cox and Klinger's model (1988), Cooper (1994) proposed a four-factor model of drinking motivations: enhancement (internal, positive reinforcement; e.g., getting high or excited), social (external, positive reinforcement; e.g., socializing with friends), coping (internal, negative reinforcement; e.g., altering bad moods), and conformity (external, negative reinforcement; e.g., fitting in the group). These four motives are expected to be positively associated with hazardous drinking, but their effect strength may vary across cultures. In adult and university samples in Australia and the US, individuals who drank for coping and enhancement motives tended to drink with increased frequency and quantities and experience more negative consequences compared to those who drank to be social and fit it (i.e., social and conformity motives; (Hasking, Lyvers, \& Carlopio, 2011; Merrill \& Read, 2010). Another study however, reported that social motives were more prevalent than other motives among Belgian university students and students with social motives for drinking were more likely to be classified as hazardous drinkers (by AUDIT; Van Damme et al., 2013). The relationship between drinking motives and hazardous drinking among Chinese university students was investigated in this study.

Congruent with what TRA proposes, alcohol outcome expectancies contribute to the 
formation of drinking motives (Cox \& Klinger, 1988). For example, individuals who hold the belief that drinking can relieve stress tend to engage in drinking as a way to cope (Lyvers, Coundouris, Edwards, \& Thorberg, 2018). In partial and full mediation models, drinking motivations have been shown to mediate the effect of outcome expectancies on alcohol use, including drinking frequency, drinking quantity, and binge drinking, in both secondary school student and treatment samples (Galen, Henderson, \& Coovert, 2001; Kuntsche, Knibbe, Engels, \& Gmel, 2007; Urban, Kokonyei, \& Demetrovics, 2008). In previous literature, there has also been good evidence that favorable subjective norms promote drinking behavior via increasing one's motivation to drink and drinking behaviors (Marcoux \& Shope, 1997; Jennifer E Merrill, Miller, Balestrieri, \& Carey, 2016), but no study has examined the mediating role of drinking motivation between perceived parental norms and drinking behaviors. In this study, the mediating effect of four kinds of drinking motivations on the relationship between alcohol outcome expectancies / parental norms and hazardous dinking was hypothesized and tested in Chinese university students.

\section{The Present Study}

Considering the increasing prevalence of drinking and its related adverse problems among Chinese university students (Kim et al., 2009), this study aimed to identify salient cognitive factors of hazardous drinking among Chinese university students. Under the framework of TRA, we hypothesized that (1) positive alcohol outcome expectancies, perceived parental norms, and drinking motivations would be positively associated with hazardous drinking; (2) negative alcohol outcome expectancies would be negatively associated with hazardous drinking; (3) drinking motivations would mediate the effects of outcome expectancies and parental norms onto hazardous drinking. 


\section{Materials and Methods}

\section{Participants and Procedures}

We recruited 1356 Chinese university students from Hong Kong and Macao, China, who completed a self-administered anonymous questionnaire after giving their consent for participation; they received no monetary compensation. Ethics approval was obtained from the Ethics Committee of the university the corresponding author was affiliated with.

Only participants who reported engaging in drinking 3 months prior to the study (i.e., recent drinkers) were included in the analyses. Of the 988 recent drinker participants, 15 missed more than one-third of the questions and their data were removed from the analyses of this study. The remaining sample was composed of 973 participants, with roughly equal numbers of males $(476,48.9 \%)$ and females $(497,51.1 \%)$, and with age ranging between 17 and 26 years $(M=19.82, S D=1.57)$.

\section{Measures}

\section{Hazardous Drinking}

Participants completed the Alcohol Use Disorder Identification Test- Consumption (AUDIT-C; Babor et al., 2001), which has three items to measure hazardous alcohol use: frequency of drinking $(0=$ Never to $4=4$ or more times a week $)$, typical quantity $(0=1$ or 2 drinks to $4=10$ or more drinks $)$, and frequency of heavy drinking $(0=$ Never to $4=$ Daily or almost daily). Higher scores indicated a greater degree of hazardous drinking (Babor et al., 2001; Bush, Kivlahan, McDonell, Fihn, \& Bradley, 1998). Participants with a score of $\geq 3$ were considered to be hazardous drinkers (Gordon et al., 2001). The Chinese version of AUDIT-C was validated by Wu et al. (2008), and in this study, its Cronbach's alpha was .70.

\section{Drinking Motivations}


We used the Drinking Motivations Questionnaire Revised (DMQ-R) developed by Cooper (1994), which measures four motivational factors of alcohol use: social, coping, enhancement, and conformity. The DMQ-R is a 20 -item questionnaire rated and scored on a 5-point Likert scale $(1=$ Never to $5=$ Always $)$. The internal reliability of its social, coping, enhancement, and conformity scales in this study was $.89, .92, .93$ and .88 respectively.

\section{Perceived Parental Norms for Drinking}

Participants completed 15 items that include a range of injunctive norms from parents regarding a range of drinking behaviours to assess the degree to which participants perceived their parents approving drinking (Lewis et al., 2010). A sample item is "How acceptable (or unacceptable) does your parents find drinking with friends?" A 7-point Likert scales $(1=$ Strongly Unacceptable to $7=$ Strongly Acceptable) was used. Cronbach's alpha of this scale was .83 in this study.

\section{Alcohol Outcome Expectancies}

We used seven subscales (38 items) of the Comprehensive Effects of Alcohol Scale (CEAS; Fromme, Stroot, \& Kaplan, 1993) to measure four positive outcome expectancies (sociability, tension reduction, courage, sexuality) and three negative outcome expectancies (cognitive and behavioural impairment, risk and aggression, self-perception) of alcohol use. A sample item is "If I were under the influence from drinking, I would be friendly", using a 4-point Likert scale ( $1=$ Disagree to $4=$ Agree $)$. The higher the subscale score, the greater the expectancy of the corresponding outcome. The internal reliability of each subscale ranged from .68 to .90 .

\section{Demographic information}

We collected data regarding sex and age of each participant. 


\section{Statistical Analysis}

Descriptive statistics and Pearson correlation were conducted among all the variables in the study by SPSS 24 . The mediation hypotheses were tested by path analysis using AMOS 22. The full mediation model was tested firstly and modified according to the results of modification index and path coefficient. According to Hair et al.'s (2006) recommendation, goodness-of-fit statistics were used to test the model by the following fit indices: a nonsignificant $\chi^{2}$ value (although a significant value is generally expected with large sample sizes and $\geq 12$ variables), the relative Chi-square (Chi-square divided by degree of freedom; $<3$ ), Comparative Fit Index (CFI; > 0.9), Goodness of Fit Index (GFI; > 0.9), Root Mean Square Error of Approximation (RMSEA; < 0.08) and Standardized Root Mean Square Residual (SRMR; <0.08). Moreover, standardized coefficients were estimated with $95 \%$ confidence interval based on the bias-corrected percentile method with 5000 bootstrap samples.

\section{Results}

\section{Descriptive and Correlation Analyses}

The descriptive statistics of alcohol use (i.e., frequency of drinking, quantity of drinking and the frequency of having 5 or more drinks on one occasion) and hazardous drinking are presented in Table 1. The prevalence of hazardous drinking (AUDIT-C $\geq 3$ ) was $46.5 \%$ in our recent drinker sample, with a higher proportion of males $(58.4 \%)$ than females $(35.2 \%)$.

[Table 1 near here]

The correlation analysis showed that age and sex effects on hazardous drinking were mild but statistically significant $(r=.11$ and -.22 respectively, $p<.001)$. Year of study also had mild, positive relationship with hazardous drinking $(r=.06, p=.026)$. 
Consistent with Hypothesis 1, positive outcome expectancies, perceived parental norms and drinking motivations showed significant and positive relationships with hazardous drinking, in which the correlation strengths of enhancement motivation $(r=.43, p<.001)$ and social motivation $(r=.40, p<.001)$ were much stronger than other variables. In contrast to Hypothesis 2, negative outcome expectancies (i.e., impairment, risk and aggression, and selfperception) and hazardous drinking were positively correlated $(r s=.12, .27$, and .15 respectively, $p<.001)$. The results are presented in the Table 2 .

[Table 2 near here]

\section{Path Analysis}

We first tested a full mediation model, in which parental norms, positive outcome expectancies, and negative outcome expectancies were set as the predictors of four drinking motives (i.e., social, coping, enhancement, and conformity motives) while these four motives were in turn modelled to predict AUDIT-C. Demographic variables of age and sex were included as control variables and modelled to predict AUDIT-C. All predictors were allowed to covariate with each other, so were the error terms of the four drinking motives.

Demographic variables were also allowed to covary with all the predictor and mediator variables. The results of this path analysis showed a significant $\chi^{2}$ statistic, $\chi^{2}(8)=48.81, p$ $<.001$, but this was expected given our large sample size. Other model fit indices suggested good to moderate fit, $\mathrm{CFI}=.994, \mathrm{GFI}=.994, \mathrm{RMSEA}=.072(.054, .093), \mathrm{SRMR}=.013$.

However, the standardized residual covariance between parental norms and hazardous drinking was very high (4.22). We therefore tested a partial mediation model by allowing a direct path from parental norms to AUDIT-C. All the other parameters remained unchanged. The fit indices of this partial mediation model were very good, $\chi^{2}(7)=18.96, p=.008, \chi^{2} / \mathrm{df}=$ $2.71, \mathrm{CFI}=.998, \mathrm{GFI}=.997, \mathrm{RMSEA}=.042(.020, .065), \mathrm{SRMR}=.008$. As a whole the model was able to explain $28.1 \%$ of variability in the participants' AUDIT-C. Figure 1 and 
Table 3 showed the standardized coefficients (with 95\% confidence interval based on the bias-corrected percentile method with 500 bootstrap samples) of all the paths. Table 3 also showed the indirect effects and the total effects of the predictor variables on hazardous drinking.

[Figure 1 near here]

[Table 3 near here]

In the path model, sex, but not age, significantly predicted AUDIT-C, with males drinking significantly more than females. After controlling for sex, parental norms had a significant direct as well as indirect effects, mediated by social and enhancement motivations, on hazardous drinking. Together, the total effect of parental norms on AUDIT-C was .22, $95 \%$ CI $[.17, .28]$. Whereas three of the four positive expectancies (i.e., sociability, tension reduction, and courage) had significant indirect effects on AUDIT mediated by different drinking motivations, none of the three negative outcome expectances did. Courage had the strongest indirect effect on hazardous drinking through social, enhancement and coping motivations, $\beta=.12(95 \%$ CI $[.09, .17])$. The effect of tension reduction on hazardous drinking was mediated by enhancement and coping motivations $(\beta=.06,95 \% \mathrm{CI}[.02, .08])$, whereas sociality was mediated by social motivation $(\beta=.05,95 \%$ CI $[.02, .10])$.

\section{Discussion}

The prevalence of hazardous drinking was high (i.e., 46.5\%), especially for male counterparts, in our study. More than half of male students got the score 3 or more on AUDIT-C regarding their drinking in the past year. Interventions about hazardous drinking among university students is warranted. In keeping with TRA (Fishbein \& Ajzen, 2011), this study's results generally supported the notion that both positive alcohol outcome expectancies and perceived parental norms regarding drinking are significant factors of 
hazardous drinking among Chinese university students and should be considered when designing interventions.

Our findings showed the direct and indirect effects of perceived parental norms on hazardous drinking. Specifically, participants' perceptions that their parents approved of their drinking were associated with not only higher drinking motivations but also hazardous drinking directly. Consistent with previous studies, disapproval of drinking from parents appears to be an effective way to protect youths against problematic drinking behaviours and related negative consequences (Ryan, Jorm, \& Lubman, 2010). The effect of perceived parental norms on Chinese students' hazardous drinking was also mediated by drinking motivations related to socialization and enhancement. These two kinds of positive motivations are generated from external and internal sources respectively (Cooper, 1994). Our findings showed that perceived parental approval of drinking heightened one's drinking motivations via positive social reinforcement but also positive emotional states. Alcohol use is common in festive celebrations and family gatherings in the Chinese culture (Yoon, Lam, Sham, \& Lam, 2015), and young people may be motivated to drink to gain social appreciation from parents and other senior people and to obtain pleasant emotional states. A longitudinal study similarly found that parental drinking behaviours had an effect on offspring's heavy drinking by promoting the offspring's enhancement motivation (Van Damme et al., 2015). We therefore recommend that the parents to explicitly show their disapproval of their adolescent/adult children's drinking and prohibit youth drinking (for enjoyment) and family drinking (for socialization).

Of the alcohol outcome expectancies, we found positive but not negative expectancies had significant effects on hazardous drinking in the path analysis. Previous research findings regarding the effect of negative outcome expectancies were also inconclusive (e.g., Lewis \& O'Neill, 2000; Zamboanga et al., 2010). In this study, negative alcohol outcome expectancies 
had only mild, but positive, correlations with hazardous drinking. Such unexpected associations possibly reflect causality issues due to the cross-sectional nature of the study, as those who engaged in more hazardous drinking would be more likely to experience adverse alcohol outcomes and thus to possess more negative outcome expectancies of drinking. Longitudinal research is warranted. Another plausible reason is that some young people may intentionally drink for self-handicapping and risk-taking reasons (Coleman \& Cater, 2005). It is important to note, however, that the path analysis results showed that negative outcome expectancies had neither direct nor indirect effect on hazardous drinking. These results suggest that knowledge of negative consequences of drinking might not deter university students from engaging in hazardous drinking. Education efforts about the adverse health consequences of hazardous drinking, therefore, may have little effect on preventing university students from engaging in hazardous drinking.

As hypothesized, a higher motivation (regardless of types) was positively associated with hazardous drinking. Furthermore, all motivations, but conformity, played mediating roles between TRA variables and hazardous drinking in our path model. Our findings echoed previous research that has shown drinking motivation to be the most proximal factor of alcohol use, which mediated the effects of other personality (e.g., sensation-seeking) and cognitive (e.g., outcome expectancy) factors among adolescents (Kuntsche et al., 2007; Urban et al., 2008). This study showed that the effects of all positive alcohol outcome expectancies were fully mediated by three drinking motivations (i.e., social rewards, mood enhancement, and problem coping) among Chinese university students. The findings suggest that preventive measures would be more effective if they employ cognitive strategies to alter specific positive, but not negative, outcome expectancies of alcohol use and in turn lower young adults' corresponding drinking motivations. 
This study further demonstrated that different alcohol outcome expectancies are involved in diverse motivational mechanisms of drinking. Among the four positive outcome expectancies, courage had the strongest effect on hazardous drinking, by promoting one's social, enhancement and coping motivations. This finding suggests that the anticipation of having more courage after drinking may activate not only the motivational mechanism for both internal and external rewards, but also a motivation to avoid or escape unwanted moods and worries. Regarding tension reduction outcome expectancy, we found its effect on hazardous drinking was mediated by only enhancement motivation. Enhancement motivation, with expectations of positive affect enhancement, has also been reported to make university students inclined to drink more in previous research (Read, Wood, Kahler, Maddock, \& Palfai, 2003). As expected, the effect of sociality outcome expectancy on hazardous drinking was mediated by social motivations. Drinking in social contexts (e.g., parties and ceremonies) is common among Chinese university students (Ma \&Fan, 2000). Sexuality outcome expectancies was also positively related to hazardous drinking mediated by coping motivations. Although its indirect effect size was found mild and non-significant, the role of alcohol use on the relationship between coping to reduce stress and Chinese university students' sexual behaviours warrants further research.

Limitations of this study should be noted. First, our convenience sample limits the generalizability of the findings to Chinese students in rural regions of China. Second, the cross-sectional design is not capable of determining causation among the psychological factors. Moreover, TRA has been further extended by its developers to the Theory of Planned Behaviour (Fishbein \& Ajzen, 2011), which includes perceived behavioural control over the target behaviour that significantly associated with addictive behaviors among Chinese youths (e.g., Wu, Li, Lau, Mo, \& Lau, 2016), but this factor was not examined in the present study. 
Despite these limitations, this study was the first to empirically test the indirect effect of perceived parental norms and various alcohol outcome expectancies on hazardous drinking through drinking motivations among Chinese university students. Perceived parental norms had both direct and indirect (via social and enhancement motivations) on their hazardous drinking. Positive outcome expectancies drove university students to engage in hazardous drinking via both positive (internal and external) and negative (internal) reinforcement motivational mechanisms. Based on our findings, we proposed that effective intervention may involve not only lowering university students' positive outcome expectancies of alcohol use but also encouraging parents to establish an unfavourable social norm regarding their children's alcohol use. 


\section{References}

Anthenien, A. M., Lembo, J., \& Neighbors, C. (2017). Drinking motives and alcohol outcome expectancies as mediators of the association between negative urgency and alcohol consumption. Addictive Behaviors, 66, 101-107. doi:10.1016/j.addbeh.2016.11.009

Babor, T. F., Higgins-Biddle, J. C., Saunders, J. B., Monteiro, M. G. . (2001). AUDIT: the alcohol use disorders identification test: guidelines for use in primary health care. World Health Organization.

Bruce, G., Curren, C., \& Williams, L. (2012). Alexithymia and alcohol consumption: the mediating effects of drinking motives. Addictive Behaviors, 37(3), 350-352. doi:10.1016/j.addbeh.2011.11.024

Bush, K., Kivlahan, D. R., McDonell, M. B., Fihn, S. D., \& Bradley, K. A. (1998). The AUDIT alcohol consumption questions (AUDIT-C): an effective brief screening test for problem drinking. Archives of Internal Medicine, 158(16), 1789-1795. doi:DOI 10.1001/archinte.158.16.1789

Chen, C. Y., Storr, C. L., Liu, C. Y., Chen, K. H., Chen, W. J., \& Lin, K. M. (2011). Differential relationships of family drinking with alcohol expectancy among urban school children. $B M C$ Public Health, 11, 87. doi:10.1186/1471-2458-11-87

Coleman, L., \& Cater, S. (2005). Underage 'binge'drinking: A qualitative study into motivations and outcomes. Drugs: Education, Prevention and Policy, 12(2), 125-136.

Conner, M., McEachan, R., Lawton, R., \& Gardner, P. (2017). Applying the reasoned action approach to understanding health protection and health risk behaviors. Social Science \& Medicine, 195, 140-148. doi:10.1016/j.socscimed.2017.10.022

Cooper, M. L. (1994). Motivations for alcohol use among adolescents: Development and validation of a four-factor model. Psychological Assessment, 6(2), 117.

Cox, W. M., \& Klinger, E. (1988). A motivational model of alcohol use. Journal of Abnormal Psychology, 97(2), 168-180. doi:Doi 10.1037/0021-843x.97.2.168 
Dunne, E. M., \& Katz, E. C. (2015). Alcohol Outcome Expectancies and Regrettable DrinkingRelated Social Behaviors. Alcohol and Alcoholism, 50(4), 393-398. doi:10.1093/alcalc/agv026

Espada, J. P., Griffin, K. W., Gonzalvez, M. T., \& Orgiles, M. (2015). Predicting Alcohol-Impaired Driving among Spanish Youth with the Theory of Reasoned Action. The Spanish Journal of Psychology, 18, e43. doi:10.1017/sjp.2015.44

Fishbein, M., \& Ajzen, I. (2011). Predicting and changing behavior: The reasoned action approach. NY: Taylor \& Francis.

Fostera, D. W., Dukes, K., \& Sartor, C. E. (2016). The road to drink is paved with high intentions: Expectancies, refusal self-efficacy, and intentions among heavy drinking college students. Alcohol, 50, 65-71. doi:10.1016/j.alcohol.2015.11.004

Fromme, K., Stroot, E. A., \& Kaplan, D. (1993). Comprehensive effects of alcohol: Development and psychometric assessment of a new expectancy questionnaire. Psychology Assessment, 5(1), 19.

Galen, L. W., Henderson, M. J., \& Coovert, M. D. (2001). Alcohol expectancies and motives in a substance abusing male treatment sample. Drug and Alcohol Dependence, 62(3), 205-214.

Giancola, P. R. (2002). Alcohol-related aggression during the college years: theories, risk factors and policy implications. Journal of Studies on Alcohol, Supplement(14), 129-139.

Gordon, A. J., Maisto, S. A., McNeil, M., Kraemer, K. L., Conigliaro, R. L., Kelley, M. E., \& Conigliaro, J. (2001). Three questions can detect hazardous drinkers. Journal of Family Practice, 50(4), 313-320.

Hair, J. F., Black, W. C., Babin, B. J., Anderson, R. E., \& Tatham, R. L. (2006). Multivariate data analysis (Vol. 6). In: Upper Saddle River, NJ: Pearson Prentice Hall.

Ham, L. S., Stewart, S. H., Norton, P. J., \& Hope, D. A. (2005). Psychometric assessment of the Comprehensive Effects of Alcohol Questionnaire: Comparing a brief version to the original full scale. Journal of Psychopathology and Behavioral Assessment, 27(3), 141-158. doi:10.1007/s10862-005-0631-9 
Han, S. C., \& Short, J. L. (2009). Alcohol expectancies as a mediator of the relation between impulsivity and alcohol consumption in Asian Americans. Journal of Ethnicity in Substance Abuse, 8(2), 178-200.

Hasking, P., Lyvers, M., \& Carlopio, C. (2011). The relationship between coping strategies, alcohol expectancies, drinking motives and drinking behaviour. Addictive Behaviors, 36(5), 479-487. doi:10.1016/j.addbeh.2011.01.014

Heather, N. (2011). Alcohol Use Disorders and Hazardous Drinking among Undergraduates at English Universities: a Reply to Heffernan. Alcohol and Alcoholism, 46(4), 372-372. doi:10.1093/alcalc/agr050

Howland, J., Rohsenow, D. J., Greece, J. A., Littlefield, C. A., Almeida, A., Heeren, T., . . Hermos, J. (2010). The effects of binge drinking on college students' next-day academic test-taking performance and mood state. Addiction, 105(4), 655-665. doi:10.1111/j.13600443.2009.02880.x

Ji, C. Y., Hu, P. J., \& Song, Y. (2012). The Epidemiology of Alcohol Consumption and Misuse among Chinese College Students. Alcohol and Alcoholism, 47(4), 464-472. doi:10.1093/alcalc/ags037

Jones, B. T., Corbin, W., \& Fromme, K. (2001). A review of expectancy theory and alcohol consumption. Addiction, 96(1), 57-72. doi:DOI 10.1046/j.1360-0443.2001.961575.x

Kim, J. H., Chan, K. W. C., Chow, J. K. W., Fung, K. P., Fong, B. Y. F., Cheuk, K. K., \& Griffiths, S. M. (2009). University Binge Drinking Patterns and Changes in Patterns of Alcohol Consumption Among Chinese Undergraduates in a Hong Kong University. Journal of American College Health, 58(3), 255-265. doi:Doi 10.1080/07448480903295318

Kuntsche, E., Knibbe, R., Engels, R., \& Gmel, G. (2007). Drinking motives as mediators of the link between alcohol expectancies and alcohol use among adolescents. Journal of Studies on Alcohol and Drugs, 68(1), 76-85. doi:DOI 10.15288/jsad.2007.68.76 
LaBrie, J. W., Lac, A., Kenney, S. R., \& Mirza, T. (2011). Protective behavioral strategies mediate the effect of drinking motives on alcohol use among heavy drinking college students: Gender and race differences. Addictive Behaviors, 36(4), 354-361. doi:10.1016/j.addbeh.2010.12.013

Lac, A., \& Donaldson, C. D. (2018). Testing competing models of injunctive and descriptive norms for proximal and distal reference groups on alcohol attitudes and behavior. Addictive Behaviors, 78, 153-159. doi:10.1016/j.addbeh.2017.11.024

Leavens, E. L., Leffingwell, T. R., Miller, M. B., Brett, E. I., \& Lombardi, N. (2017). Subjective evaluations of alcohol-related consequences among college students: Experience with consequences matters. Journal of American College Health, 65(4), 243-249. doi:10.1080/07448481.2016.1271803

Lewis, B. A., \& O'Neill, H. K. (2000). Alcohol expectancies and social deficits relating to problem drinking among college students. Addictive Behaviors, 25(2), 295-299. doi:Doi 10.1016/S0306-4603(99)00063-5

Lewis, M. A., Neighbors, C., Geisner, I. M., Lee, C. M., Kilmer, J. R., \& Atkins, D. C. (2010). Examining the Associations Among Severity of Injunctive Drinking Norms, Alcohol Consumption, and Alcohol-Related Negative Consequences: The Moderating Roles of Alcohol Consumption and Identity. Psychology of Addictive Behaviors, 24(2), 177-189. doi:10.1037/a0018302

Lyvers, M., Coundouris, S., Edwards, M. S., \& Thorberg, F. A. (2018). Alexithymia, reward sensitivity and risky drinking: the role of internal drinking motives. Addiction Research \& Theory, 26(2), 114-122. doi:10.1080/16066359.2017.1333110

Ma, S. B., \& Fan, C. X. (2000). A study of alcohol drinking pattern and reasons in college students. Modern Prevention Medicine, 27(1), 56-58.

Mallett, K. A., Varvil-Weld, L., Borsari, B., Read, J. P., Neighbors, C., \& White, H. R. (2013). An Update of Research Examining College Student Alcohol-Related Consequences: New Perspectives and Implications for Interventions. Alcoholism-Clinical and Experimental Research, 37(5), 709-716. doi:10.1111/acer.12031 
Marcoux, B. C., \& Shope, J. T. (1997). Application of the Theory of Planned Behavior to adolescent use and misuse of alcohol. Health Education Research, 12(3), 323-331. doi:DOI 10.1093/her/ 12.3 .323

McEachan, R., Taylor, N., Harrison, R., Lawton, R., Gardner, P., \& Conner, M. (2016). MetaAnalysis of the Reasoned Action Approach (RAA) to Understanding Health Behaviors. Annals of Behavioral Medicine, 50(4), 592-612. doi:10.1007/s12160-016-9798-4

Merrill, J. E., Miller, M. B., Balestrieri, S. G., \& Carey, K. B. (2016). Do my peers approve? Interest in injunctive norms feedback delivered online to college student drinkers. Addictive Behaviors, 58, 188-193.

Merrill, J. E., \& Read, J. P. (2010). Motivational Pathways to Unique Types of Alcohol Consequences. Psychology of Addictive Behaviors, 24(4), 705-711. doi:10.1037/a0020135

Montauti, S. B., \& Bulmer, S. M. (2014). A research update on correlates of heavy episodic drinking among undergraduate college students. American Journal of Health Education, 45(3), 142150.

Neighbors, C., O'Connor, R. M., Lewis, M. A., Chawla, N., Lee, C. A., \& Fossos, N. (2008). The Relative Impact of Injunctive Norms on College Student Drinking: The Role of Reference Group. Psychology of Addictive Behaviors, 22(4), 576-581. doi:10.1037/a0013043

Nguyen, M. L., \& Neighbors, C. (2013). Self-determination, perceived approval, and drinking: Differences between Asian Americans and Whites. Addictive Behaviors, 38(3), 1656-1662. doi:10.1016/j.addbeh.2012.10.001

Olthuis, J. V., Zamboanga, B. L., Ham, L. S., \& Van Tyne, K. (2011). The Utility of a GenderSpecific Definition of Binge Drinking on the AUDIT. Journal of American College Health, 59(4), 239-245. doi:10.1080/07448481.2010.497523

Perkins, H. W. (2002). Social norms and the prevention of alcohol misuse in collegiate contexts. Journal of Studies on Alcohol, Supplement (14) 164-172. doi:DOI $10.15288 /$ jsas.2002.s 14.164 
Phua, J. (2011). The influence of peer norms and popularity on smoking and drinking behavior among college fraternity members: A social network analysis. Social Influence, 6(3), 153-168. doi:10.1080/15534510.2011.584445

Read, J. P., Wood, M. D., Kahler, C. W., Maddock, J. E., \& Palfai, T. P. (2003). Examining the role of drinking motives in college student alcohol use and problems. Psychology of Addictive Behaviors, 17 (1), 13.

Reid, M. C., Fiellin, D. A., \& O'Connor, P. G. (1999). Hazardous and harmful alcohol consumption in primary care. Archives of Internal Medicine, 159(15), 1681-1689. doi:DOI 10.1001/archinte.159.15.1681

Ryan, S. M., Jorm, A. F., \& Lubman, D. I. (2010). Parenting factors associated with reduced adolescent alcohol use: a systematic review of longitudinal studies. Australian and New Zealand Journal of Psychiatry, 44(9), 774-783. doi:Doi 10.1080/00048674.2010.501759

Tang, Y. L., Xiang, X. J., Wang, X. Y., Cubells, J. F., Babor, T. F., \& Hao, W. (2013). Alcohol and alcohol-related harm in China: policy changes needed. Bulletin of the World Health Organization, 91(4), 270-276. doi:10.2471/BLT.12.107318

Ting, T. T., Chen, W. J., Liu, C. Y., Lin, Y. C., \& Chen, C. Y. (2015). Peer influences on alcohol expectancies in early adolescence: A study of concurrent and prospective predictors in Taiwan. Addictive Behaviors, 40, 7-15. doi:10.1016/j.addbeh.2014.08.001

Urban, R., Kokonyei, G., \& Demetrovics, Z. (2008). Alcohol outcome expectancies and drinking motives mediate the association between sensation seeking and alcohol use among adolescents. Addictive Behaviors, 33(10), 1344-1352. doi:10.1016/j.addbeh.2008.06.006

Van Damme, J., Maes, L., Clays, E., Rosiers, J. F., Van Hal, G., \& Hublet, A. (2013). Social motives for drinking in students should not be neglected in efforts to decrease problematic drinking. Health Education Research, 28(4), 640-650.

Van Damme, J., Maes, L., Kuntsche, E., Crutzen, R., De Clercq, B., Van Lippevelde, W., \& Hublet, A. (2015). The influence of parental drinking on offspring's drinking motives and drinking: A 
mediation analysis on 9 year follow-up data. Drug and Alcohol Dependence, 149, 63-70. doi:10.1016/j.drugalcdep.2015.01.020

White, A., \& Hingson, R. (2013). The Burden of Alcohol Use Excessive Alcohol Consumption and Related Consequences Among College Students. Alcohol Research Current Reviews, 35(2), 201-218.

World Health Organization. (2014). Global status report on alcohol and health, 2014. World Health Organization. Retrieved by http://www.who.int/substance_abuse/publications/global_alcohol_report/en/

Wu, A. M. S., Li, J. B., Lau, J. T. F., Mo, P. K. H., \& Lau, M. M. C. (2016). Potential impact of internet addiction and protective psychosocial factors onto depression among Hong Kong Chinese adolescents - direct, mediation and moderation effects. Comprehensive Psychiatry, 70, 41-52. doi:10.1016/j.comppsych.2016.06.011

Wu, S. I., Huang, H. C., Liu, S. I., Huang, C. R., Sun, F. J., Chang, T. Y., . . Jeng, K. S. (2008). Validation and comparison of alcohol-screening instruments for identifying hazardous drinking in hospitalized patients in Taiwan. Alcohol and Alcoholism, 43(5), 577-582. doi:10.1093/alcalc/agn036

Wu, T. Y., \& Jwo, J. L. (2005). A prospective study on changes of cognitions, interpersonal influences, and physical activity in Taiwanese youth. Research Quarterly for Exercise and Sport, 76(1), 1-10.

Xu, Z. \& Deng, Y. L. (2016). Dangerous and harmful drinking and influencing factors in college students. Chinese Journal of Clinical Psychology, 24(1), 36-40.

Yoon, S., Lam, W. W., Sham, J. T., \& Lam, T. H. (2015). Learning to drink: How Chinese adolescents make decisions about the consumption (or not) of alcohol. International Journal of Drug Policy, 26(12), 1231-1237.

Zamboanga, B. L., Schwartz, S. J., Ham, L. S., Borsari, B., \& Van Tyne, K. (2010). Alcohol Expectancies, Pregaming, Drinking Games, and Hazardous Alcohol Use in a Multiethnic 
Sample of College Students. Cognitive Therapy and Research, 34(2), 124-133.

doi:10.1007/s10608-009-9234-1

Zehe, J. M., Colder, C. R., Read, J. P., Wieczorek, W. F., \& Lengua, L. J. (2013). Social and generalized anxiety symptoms and alcohol and cigarette use in early adolescence: The moderating role of perceived peer norms. Addictive Behaviors, 38(4), 1931-1939. doi:10.1016/j.addbeh.2012.11.013 
Table 1 The alcohol use and hazardous drinking among Chinese university students $(\mathrm{n}=973)$.

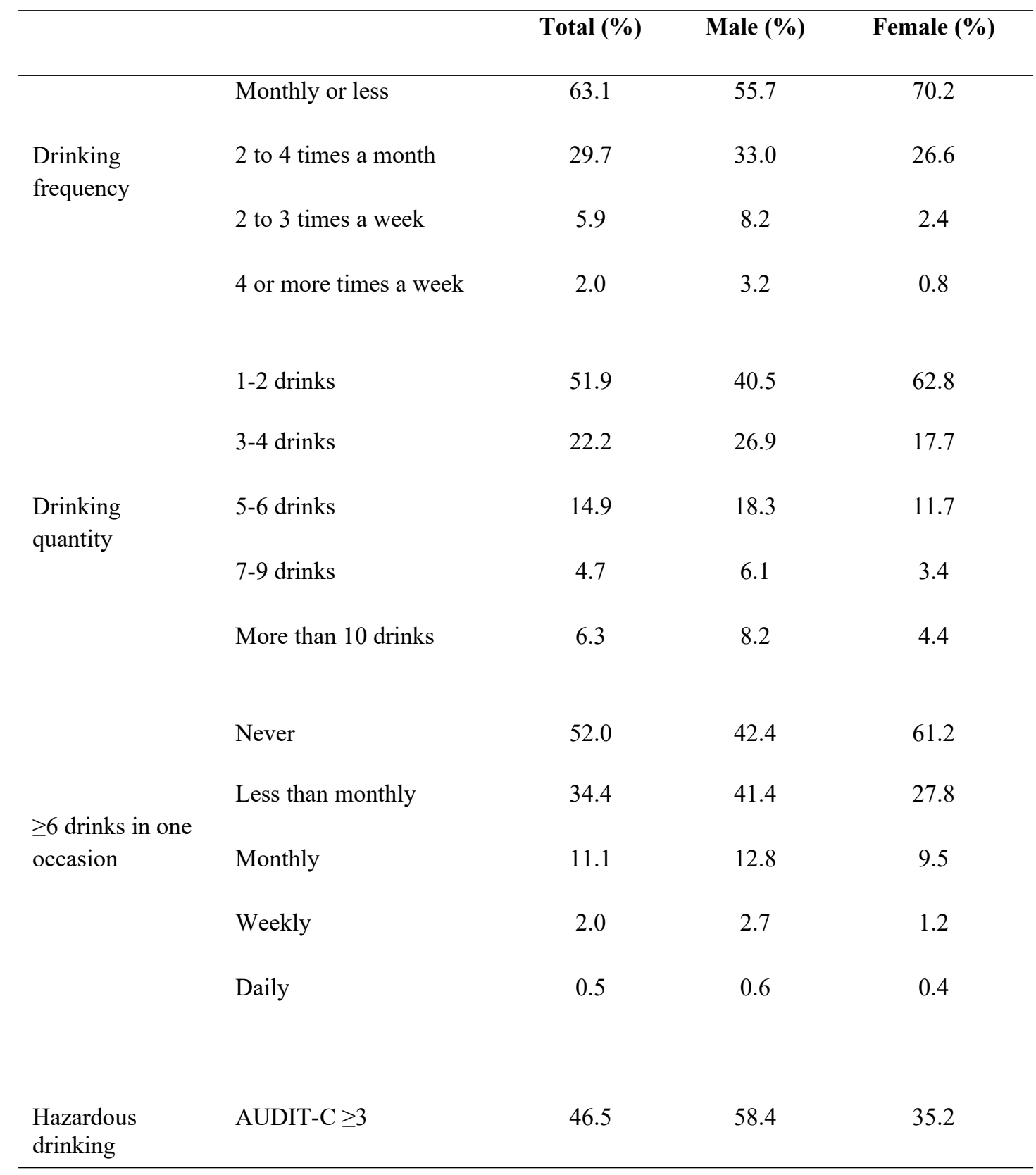


Table 2 Descriptive statistics and correlations of all the variables

\begin{tabular}{|c|c|c|c|c|c|c|c|c|c|c|c|c|c|c|c|c|c|}
\hline & M & SD & 1 & 2 & 3 & 4 & 5 & 6 & 7 & 8 & 9 & 10 & 11 & 12 & 13 & 14 & 15 \\
\hline 1.AUDIT-C & 3.01 & $\begin{array}{l}2.1 \\
7\end{array}$ & 1.00 & & & & & & & & & & & & & & \\
\hline 2.Parental norms & 3.49 & $\begin{array}{l}4.4 \\
9\end{array}$ & $.28^{* * *}$ & 1.00 & & & & & & & & & & & & & \\
\hline 3.COEA-Soc & 2.45 & .69 & $.24^{* * *}$ & $.25^{* * *}$ & 1.00 & & & & & & & & & & & & \\
\hline 4.COEA-TR & 2.30 & .68 & $.19^{* * *}$ & $.22^{* * *}$ & $.56^{* * *}$ & 1.00 & & & & & & & & & & & \\
\hline 5.COEA-C & 2.24 & .71 & $.25^{* * *}$ & $.20^{* * *}$ & $.73^{* * *}$ & $.56^{* * *}$ & 1.00 & & & & & & & & & & \\
\hline 6.COEA-Sex & 1.94 & .67 & $.25^{* * *}$ & $.23^{* * *}$ & $.59^{* * *}$ & $.48^{* * *}$ & $.62^{* * *}$ & 1.00 & & & & & & & & & \\
\hline 7.COEA-I & 2.38 & .59 & $.12^{* * *}$ & $.16^{* * *}$ & $.35^{* * *}$ & $.30^{* * *}$ & $.39^{* * *}$ & $.41^{* * *}$ & 1.00 & & & & & & & & \\
\hline 8.COEA-R & 2.05 & .60 & $.27^{* * *}$ & $.16^{* * *}$ & $.68^{* * *}$ & $.51^{* * *}$ & $.73^{* * *}$ & $.69^{* * *}$ & $.53^{* * *}$ & 1.00 & & & & & & & \\
\hline 9.COEA-SP & 1.91 & .61 & $.15^{* * *}$ & $.07^{*}$ & $.39^{* * *}$ & $.31^{* * *}$ & $.43^{* * *}$ & $.55^{* * *}$ & $.62^{* * *}$ & $.66^{* * *}$ & 1.00 & & & & & & \\
\hline 10.DMQ-S & 15.47 & $\begin{array}{l}4.8 \\
2\end{array}$ & $.40^{* * *}$ & $.29^{* * *}$ & $.48^{* * *}$ & $.30^{* * *}$ & $.45^{* * *}$ & $.34^{* * *}$ & $.20^{* * *}$ & $.36^{* * *}$ & $.15^{* * *}$ & 1.00 & & & & & \\
\hline 11.DMQ-E & 11.29 & $\begin{array}{l}5.2 \\
6\end{array}$ & $.43^{* * *}$ & $.25^{* * *}$ & $.44^{* * *}$ & $.42^{* * *}$ & $.50^{* * *}$ & $.40^{* * *}$ & $.22^{* * *}$ & $.43^{* * *}$ & $.23^{* * *}$ & $.15^{* * *}$ & 1.00 & & & & \\
\hline 12.DMQ-Cop & 11.90 & $\begin{array}{l}5.3 \\
6\end{array}$ & $.37^{* * *}$ & $.18^{* * *}$ & $.43^{* * *}$ & $.44^{* * *}$ & $.50^{* * *}$ & $.45^{* * *}$ & $.34^{* * *}$ & $.48^{* * *}$ & $.35^{* * *}$ & $.55^{* * *}$ & $.61^{* * *}$ & 1.00 & & & \\
\hline 13.DMQ-Con & 10.23 & $\begin{array}{l}4.4 \\
9\end{array}$ & $.18^{* * *}$ & $.09^{* *}$ & $.31^{* * *}$ & $.18^{* * *}$ & $.31^{* * *}$ & $.37^{* * *}$ & $.25^{* * *}$ & $.38^{* * *}$ & $.34^{* * *}$ & $.42^{* * *}$ & $.35^{* * *}$ & $.36^{* * *}$ & 1.00 & & \\
\hline 14. Age & 19.82 & $\begin{array}{l}1.5 \\
7\end{array}$ & $.11^{* * *}$ & -.05 & $.11^{* *}$ & $.15^{* * *}$ & $.14^{* * *}$ & $.07^{*}$ & $.15^{* * *}$ & $.14^{* * *}$ & $.07^{*}$ & $.09^{* *}$ & $.11^{* * *}$ & $.10^{* * *}$ & .01 & 1.00 & \\
\hline 15. Sex & - & - & $-.22^{* * *}$ & -.03 & $-.11^{* * *}$ & $-.13^{* * *}$ & $-.12^{* * *}$ & $-.09^{* * *}$ & $-.13^{* * *}$ & $-.14^{* * * *}$ & $-.12^{* * *}$ & $-.12^{* * *}$ & $-.12^{* * * *}$ & $-.13^{* * * *}$ & $-.19^{* * *}$ & $-.24^{* * *}$ & $\begin{array}{l}1.0 \\
0 \\
\end{array}$ \\
\hline
\end{tabular}

COEA-SOc represents sociality outcome expectancy; COEA-TR represents tension reduction outcome expectancy; COEA-C represents courage outcome expectancy; COEASex represents sexuality outcome expectancy; COEA-I represents impairment outcome expectancy; COEA-R represents risk outcome expectancy; COEA-SP represents selfperception outcome expectancy.

DMQ-S represents social motivation; DMQ-E represents enhancement motivation; DMQ-Cop represents coping motivation; DMQ-Con represents conformity motivation.

AUDIT-C represents hazardous drinking. 
Table 3 Standardized direct effects, indirect effects, and total effects (with $95 \%$ CI based on the bias-corrected percentile method with 5000 bootstrap samples) in the final partial mediation model

\begin{tabular}{|c|c|c|c|c|c|c|c|c|c|c|c|c|c|c|}
\hline $\begin{array}{l}\text { Direct } \\
\text { effects }\end{array}$ & Sex & Age & $\begin{array}{l}\text { Parental } \\
\text { Norms }\end{array}$ & COEA-Soc & COEA-TR & COEA-C & COEA-Sex & COEA-I & COEA-R & COEA-SP & DMQ-S & DMQ-E & $\begin{array}{l}\text { DMQ- } \\
\text { Cop }\end{array}$ & DMQ-Con \\
\hline DMQ-S & & & $\begin{array}{l}.17 * * * \\
(.11, .24)\end{array}$ & $\begin{array}{l}.28 * * * \\
(.19, .37)\end{array}$ & $\begin{array}{l}-.03 \\
(-.10, .05)\end{array}$ & $\begin{array}{l}.21 * * * \\
(.11, .29)\end{array}$ & $\begin{array}{l}.06 \\
(-.02, .15)\end{array}$ & $\begin{array}{l}.04 \\
(-.04, .15)\end{array}$ & $\begin{array}{l}.02 \\
(-.09, .14)\end{array}$ & $\begin{array}{l}-.12 * * \\
(-.21,-.03)\end{array}$ & & & & \\
\hline DMQ-E & & & $\begin{array}{l}.13 * * * \\
(.06, .18)\end{array}$ & $\begin{array}{l}.04 \\
(-.05, .13)\end{array}$ & $\begin{array}{l}.15^{* * *} \\
(.08, .21)\end{array}$ & $\begin{array}{l}.27 * * * \\
(.18, .36)\end{array}$ & $\begin{array}{l}.07 \\
(-.01, .16)\end{array}$ & $\begin{array}{l}-.02 \\
(-.10, .05)\end{array}$ & $\begin{array}{l}.11^{*} \\
(.00, .23)\end{array}$ & $\begin{array}{l}-.05 \\
(-.14, .06)\end{array}$ & & & & \\
\hline DMQ-Cop & & & $\begin{array}{l}.05 \\
(-.00, .12)\end{array}$ & $\begin{array}{l}-.01 \\
(-.11, .07)\end{array}$ & $\begin{array}{l}.19 * * * \\
(.13, .26)\end{array}$ & $\begin{array}{l}.23 * * * \\
(.15, .32)\end{array}$ & $\begin{array}{l}.11 * * \\
(.03, .19)\end{array}$ & $\begin{array}{l}-.03 \\
(-.10, .19)\end{array}$ & $\begin{array}{l}.09 \\
(-.01, .18)\end{array}$ & $\begin{array}{l}.09 * \\
(.00, .19)\end{array}$ & & & & \\
\hline DMQ-Con & & & $\begin{array}{l}.01 \\
(-.05, .06)\end{array}$ & $\begin{array}{l}.10^{*} \\
(.01, .20)\end{array}$ & $\begin{array}{l}-.08^{*} \\
(-.16,-.01)\end{array}$ & $\begin{array}{l}.01 \\
(-.09, .11)\end{array}$ & $\begin{array}{l}.17 * * * \\
(.07, .26)\end{array}$ & $\begin{array}{l}.02 \\
(-.07, .08)\end{array}$ & $\begin{array}{l}.13^{*} \\
(.02, .24)\end{array}$ & $\begin{array}{l}.14 * * \\
(.05, .24)\end{array}$ & & & & \\
\hline AUDIT-C & $\begin{array}{l}-.16 * * * \\
(-.23,-.11)\end{array}$ & $\begin{array}{l}.02 \\
(-.04, .08)\end{array}$ & $\begin{array}{l}.15 * * * \\
(.09, .21)\end{array}$ & & & & & & & & $\begin{array}{l}.19 * * * \\
(.09, .26)\end{array}$ & $\begin{array}{l}.21 * * * \\
(.13, .29)\end{array}$ & $\begin{array}{l}.13 * * * \\
(.05, .20)\end{array}$ & $\begin{array}{l}-.06 \\
(-.13, .02)\end{array}$ \\
\hline \multicolumn{15}{|l|}{$\begin{array}{l}\text { Indirect } \\
\text { effects }\end{array}$} \\
\hline AUDIT-C & & & $\begin{array}{l}.07 * * \\
(.04, .10)\end{array}$ & $\begin{array}{l}.05^{* *} \\
(.02, .10)\end{array}$ & $\begin{array}{l}.06 * * \\
(.02, .08)\end{array}$ & $\begin{array}{l}.12 * * \\
(.09, .17)\end{array}$ & $\begin{array}{l}.03 \\
(-.01, .06)\end{array}$ & $\begin{array}{l}-.00 \\
(-.03, .03)\end{array}$ & $\begin{array}{l}-.03 \\
(-.07, .02)\end{array}$ & $\begin{array}{l}.03 \\
(-.02, .08)\end{array}$ & & & & \\
\hline \multicolumn{15}{|l|}{$\begin{array}{l}\text { Total } \\
\text { effects }\end{array}$} \\
\hline AUDIT-C & $\begin{array}{l}-.16^{* * *} \\
(-.23,-.11)\end{array}$ & $\begin{array}{l}.02 \\
(-.04, .08)\end{array}$ & $\begin{array}{l}.22 * * * \\
(.17, .28)\end{array}$ & $\begin{array}{l}.05^{* *} \\
(.02, .10)\end{array}$ & $\begin{array}{l}.06^{* *} \\
(.02, .08)\end{array}$ & $\begin{array}{l}.12 * * \\
(.09, .17)\end{array}$ & $\begin{array}{l}.03 \\
(-.01, .06)\end{array}$ & $\begin{array}{l}-.00 \\
(-.03, .03)\end{array}$ & $\begin{array}{l}-.03 \\
(-.07, .02)\end{array}$ & $\begin{array}{l}.03 \\
(-.02, .08)\end{array}$ & $\begin{array}{l}.19^{* *} \\
(.09, .26)\end{array}$ & $\begin{array}{l}.21^{* * *} \\
(.13, .29)\end{array}$ & $\begin{array}{l}.13^{* * *} \\
(.05, .20)\end{array}$ & $\begin{array}{l}-.06 \\
(-.13, .02)\end{array}$ \\
\hline
\end{tabular}

COEA-SOc represents sociality outcome expectancy; COEA-TR represents tension reduction outcome expectancy; COEA-C represents courage outcome expectancy; COEASex represents sexuality outcome expectancy; COEA-I represents impairment outcome expectancy; COEA-R represents risk outcome expectancy; COEA-SP represents selfperception outcome expectancy.

DMQ-S represents social motivation; DMQ-E represents enhancement motivation; DMQ-Cop represents coping motivation; DMQ-Con represents conformity motivation.

AUDIT-C represents Alcohol Use Disorder Identification Test- Consumption. 


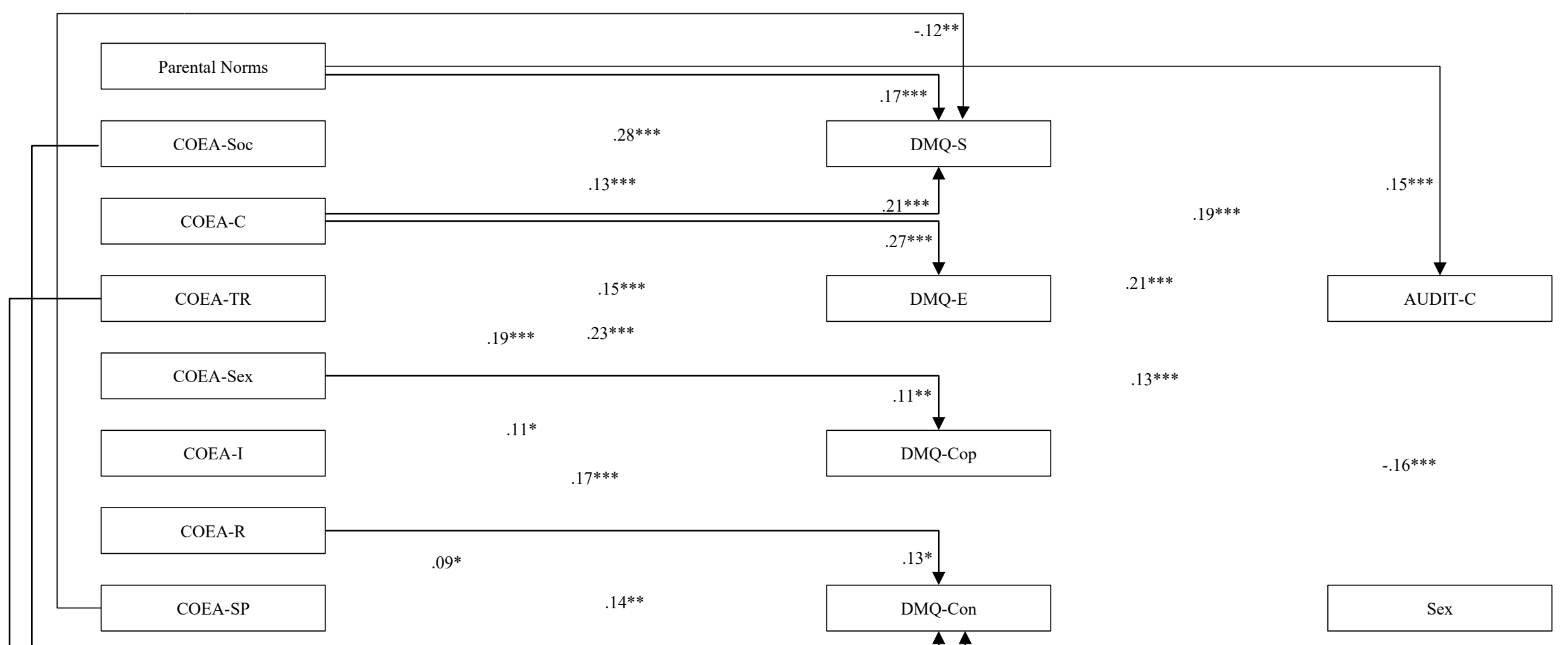

\footnotetext{
Note: *: $p<.05 ; * *: p<.01 ; * * *: p<.001$. Only the significant directional paths are presented in the figure.
}

Figure 1 The Standardized Coefficients in the Path Model

COEA-Soc represents sociality outcome expectancy; COEA-TR represents tension reduction outcome expectancy; COEA-C represents courage outcome expectancy; COEA-Sex represents sexuality outcome expectancy; COEA-I represents impairment outcome expectancy; COEA-R represents risk outcome expectancy; COEA-SP represents self-perception outcome expectancy.

DMQ-S represents social motivation; DMQ-E represents enhancement motivation; DMQ-Cop represents coping motivation; DMQ-Con represents conformity motivation; AUDIT-C represents Alcohol Use Disorder Identification Test- Consumption. 